\title{
MARCOS DA EXTENSÃO NOS 25 ANOS DE EDUCAÇÃO EM BIBLIOTECONOMIA DA UNIVERSIDADE FEDERAL DE SANTA CATARINA
}

\author{
Prof $^{a}$. Adjunto Maria Margarete Sell da Mata \\ Departamento de Biblioteconomia e Documentação da \\ Universidade Federal de Santa Catarina - e-mail: margaret@ced.ufsc.br
}

\section{RESUMO}

Relata as principais atividades de extensão do Departamento de Biblioteconomia da Universidade Federal de Santa Catarina no período de 1973 a 1998, dando ênfase ao programa de estágio

PALAVRAS-CHAVE: Atividades de biblioteconomia, Estágio em Biblioteconomia, Curso de Biblioteconomia

\begin{abstract}
Describes the non-tutorial program of the Department of Library Science of the Federal University of Santa Catarina, at Florianópolis, Brazil, with special emphasis on the training program.
\end{abstract}

KEYWORDS: Training program - library science, Non-tutorial program - Library Science, Librarianship

\section{ATIVIDADES DE BIBLIOTECONOMIA}

A extensão, um dos segmentos da Universidade Federal de Santa Catarina - UFSC, tem sido uma das atividades desenvolvidas pelos professores do Departamento de Biblioteconomia e Documentação - BDC, com destaque nas categorias de consultoria e assessoria.

Assim, o BDC ao executar trabalho extensionista, tem se pautado na definição estabelecida pela UFSC, e regulamentada pela Resolução 31/CEPE/93, que é "entendida como uma das funções básicas da universidade. É a interação sistematizada da universidade com a comunidade, através da mútua prestação de serviços, visando contribuir para o desenvolvimento da comunidade e dela buscar conhecimentos e experiências para a avaliação e vitalização do ensino e da pesquisa".

Seguindo esta definição, o Centro de Ciências da Educação - CED, cujo centro de ensino o BDC pertence, traçou sua linha de extensão voltada para:

"formação continuada de educadores e bibliotecários; assessorias na área de educação e unidades de informação; projetos específicos"1.

Ao longo dos 25 anos de educação em Biblioteconomia da UFSC foram desenvolvidas várias atividades de extensão com o objetivo de promover uma interação sistematizada da universidade com a comunidade.

Para este evento e em função das disponibilidade de tempo cedido a esta seção, selecionamos três atividades de extensão, desenvolvidas nas décadas de 70, 80 e 90.

Nas décadas de 70 e 80, desenvolveu-se o projeto "Casa da Cultura (Biblioteca Pública Municipal Paulo Rodrigues dos Santos) e Núcleo de Atividades Artísticas e Culturais”, cujos objetivos foram pautados na difusão da leitura através da Hora do Conto e no exercício de atividades recreativas desenvolvidas no Domingo da Praça.

Este projeto foi desenvolvido, durante o período de 1979-1982, em Santarém (PA), através do Projeto Rondon que tinha como lema "Integrar para não entregar". A contribuição e a participação da UFSC neste programa

Enc. Bibli: R. Eletr. Bibliotecon. Ci. Inf., ISSN 1518-2924, Florianópolis, Brasil. 
deu-se por intermédio dos Cursos de Graduação em Agronomia (orientação a comunidade carente na elaboração de hortas caseiras), Arquitetura (com projetos arquitetônicos para a população carente), Direito (expedição de registro de certidões de nascimento), Enfermagem e Medicina (prevenção e orientação de doenças, bem como atendimento médico), Serviço Social (trabalho com mães solteiras, na auxílio de pesquisa paternidade). O Curso de Biblioteconomia assumiu a divulgação do hábito de leitura e hora do conto. Para tanto, criaram um serviço de Caixas Estantes, beneficiando diretamente as populações ribeirinhas, cujo acesso ao local era feito por barcos, onde a cada 90 dias os alunos de Biblioteconomia se dirigiam aos locais préestabelecidos para troca e rotatividade do acervo de livros das Caixas Estantes. Esta atividade foi muito significativa para a população beneficiada, pois as crianças em sua maioria nunca tinham antes visto um livro, só tinham contato com a lousa.

O Domingo na Praça, que consistia no exercício de desenvolver e praticar habilidades recreativas, foi outra atividade marcante, desenvolvida em bairros periféricos de Santarém. Também, neste projeto, foram oferecidos cursos intensivos para auxiliares de bibliotecas, ministrados por professores de Biblioteconomia da UFSC.

A Casa da Cultura de Santarém, sede da Biblioteca Pública da Cidade, teve sua arquitetura reformulada com a participação de alunos de arquitetura, cuja idealização do projeto da Biblioteca foi de autoria de uma professora de Biblioteconomia da UFSC e implementado por alunos de Biblioteconomia.

Este projeto conhecido também como Campus Avançado de Santarém, desenvolvido pela UFSC, encerrou suas atividades durante o Governo Collor, em 1992, e coube a Universidade de Belém a continuidade dos trabalhos.

Podemos destacar como impacto desta experiência a visibilidade da Biblioteconomia no contexto das comunidades de Santarém.

Na década de 80 elegemos o sub-projeto "Educação para leitura" do projeto "Curso de Português - teoria e prática - PORTEPRÁ”, pertencente ao Programa de Integração da Universidade com o Ensino de 1o Grau SDE/SESU/MEC/FNDE.

Este projeto foi executado por uma equipe interdisciplinar de professores das áreas de biblioteconomia, letras e metodologia do ensino, bem como alunos dos três cursos, com atuação em municípios da Grande Florianópolis.

Sua execução iniciou-se em 1985, estendendo-se até 1986, onde não foi dado continuidade por falta de definições de políticas públicas no Brasil.

Seu objetivo geral era o de despertar, a partir de atividades de leitura e empréstimo de livros, o gosto pela leitura, utilizando obras de literatura, como recurso de ensino-aprendizagem, além de estimular a criação de ambiente favorável para a leitura em família, visando a instalação de bibliotecas comunitárias sediadas em escolas públicas.

E este projeto foi dividido geograficamente em quatro regiões, permitindo, assim, que a distribuição dos livros em cada escola fosse feita dentro de uma periodicidade proporcionando o recebimento de livros em cada turma de alunos uma vez por mês. Portanto, cada região recebia, mensalmente, a visita da equipe do projeto. Foram orientados professores para a realização de atividades buscando criar e sedimentar o gosto pela leitura.

O impacto deste projeto impulsionou e estimulou os professores de ensino de 10 grau, a participarem na UFSC de cursos de orientações dentro dos vários sub-projetos, como podemos destacar o presente com a promoção da leitura, levando o livro numa perspectiva informal e permeando, na medida do possível, todas as disciplinas do currículo do ensino de 10 grau. Ainda, quanto a atuação junto a comunidade escolar os depoimentos dos professores envolvidos neste projeto, são testemunhos da importância da biblioteca e quanto

Enc. Bibli: R. Eletr. Bibliotecon. Ci. Inf., ISSN 1518-2924, Florianópolis, Brasil. 
o trabalho de Biblioteconomia fortalecido pela Coordenação do PORTEPRÁ, foi bem recebido e obteve bons resultados.

Destacamos na década de 90 o projeto “Arquivo Fotográfico : gerenciamento de imagem”, cujas atividades foram iniciadas em 1994, com o cumprimento de seu objetivo maior, que é a "organização do Arquivo Fotográfico : gerenciamento da imagem, visando conservar e tornar acessível a documentação fotográfica sob a custódia do Instituto Histórico e Geográfico de Santa Catarina”.

Tal atividade vem sendo executada no Instituto Histórico e Geográfico de Santa Catarina (Florianópolis), sob a coordenação de um docente de biblioteconomia e com a participação de alunos estagiários dos Cursos de Biblioteconomia e História da UFSC.

O impacto deste projeto vem de encontro com o interesse e a valorização crescente da imagem fotográfica, organizada e disponibilizada ao usuário dentro dos recursos impostos pelas novas tecnologias da informação de imagens computadorizadas. O projeto permite que as informações do Arquivo Fotográfico do Instituto, sejam recuperadas rapidamente, ao mesmo tempo em que se preservam os suportes originais, evitando o seu constante manuseio. Este projeto para a sociedade aponta, dentro de um profissionalismo ímpar, para um trabalho integrado e cooperativo com outras instituições congêneres, que vem sendo realizado a nível nacional, sob o comando do Arquivo Nacional, no sentido de incentivar o uso da fotografia enquanto fonte histórica, sugerindo o resgate de um conteúdo significativo e possibilitando sua valorização na construção da memória social. Assim, este projeto vem proporcionando o acesso as fotografias, aos sócios do Instituto, a comunidade universitária e a comunidade em geral. Para a educação em Biblioteconomia da UFSC, este campo, promove o aprimoramento científico no uso de novas tecnologias da informação.

O estágio é, conforme sua vivência prática, uma atividade de extensão no BDC, se levarmos em consideração o seu significado para a UFSC. Assim sendo a universidade define como tal aquele "período de exercício préprofissional em que o estudante participa diretamente de um ambiente de trabalho, convivendo com uma realidade imposta pela sociedade, desenvolvendo atividades profissionalizantes, com duração limitada e supervisão constante", .

Os estágios do Curso de Biblioteconomia atendem a duas modalidades; obrigatório e não-obrigatório. $\mathrm{O}$ estágio obrigatório obrigatório é realizado na disciplina Estágio Supervisionado em Biblioteconomia, sob a orientação e supervisão de um Bibliotecário e um professor do BDC, numa unidade de informação. Já o estágio não-obrigatório constitui-se em atividade complementar à formação do acadêmico, realizado por livre escolha do mesmo, desde que esteja regularmente matriculado em qualquer fase do Curso de Biblioteconomia ${ }^{3}$.

O estágio permite preparar o acadêmico para uma realidade profissional, através da complementação e aprimoramento educacional, consolidando a união entre o ensino teórico e prático, entre o saber e o fazer, na busca do aperfeiçoamento profissional.

Através de um estágio bem planejado, bem orientado, tendo como objeto maior a busca do aperfeiçoamento profissional, temos certeza que o mesmo promove uma abertura de mercado de trabalho.

Nossa afirmação encontra sustentação ao destacarmos experiências vivenciadas por alunos do Curso de Biblioteconomia da UFSC, ao realizarem estágios de qualidade e que permitiram sua projeção no mercado de trabalho.

Dentro deste contexto, podemos registrar a abertura de vagas na Universidade do Planalto Catarinense, em Lages, para alunos recém-formados que obtiveram relevante desempenho no estágio obrigatório. Também, deve-se registrar a recente contratação de uma bibliotecária na empresa Intelecto Software Ltda., marca de fantasia Digilab, em Florianópolis.

Enc. Bibli: R. Eletr. Bibliotecon. Ci. Inf., ISSN 1518-2924, Florianópolis, Brasil. 
Ainda, como resultados de desempenhos satisfatórios de estágios de acadêmicos, merece destaque, por ocasião da comemoração da Semana Nacional do Livro e da Biblioteca, a nível de Santa Catarina, em outubro de 1998, o lançamento de produtos de serviços da Biblioteca Universitária da UFSC. Das 7 bases de dados disponibilizadas aos usuários da referida biblioteca, 4 contaram com a participação de alunos do Curso de Biblioteconomia, como atividades programadas e executadas durante o estágio obrigatório.

\section{CONSIDERAÇÕES FINAIS}

Finalizando, o aspecto do estágio, deixamos como reflexão para os acadêmicos de biblioteconomia, o recente depoimento de uma aluna do Curso ao encerrar seu período de estágio e daqui para frente deverá "ir a lutar" para disputar um espaço no mercado de trabalho. O depoimento nos diz o seguinte: "pudemos constatar o quanto é importante a realização do estágio durante a vida acadêmica, possibilitando-nos a reunião de experiências para a futura vida profissional. Na prática cotidiana deparamo-nos com muitas situações que exigiram poder criativo para efetuarmos adaptações, ampliando nossa visão, anteriormente um tanto quanto limitadas pelo próprio acúmulo de bagagem teórica durante o Curso, quando ainda não tínhamos a preocupação em relacionar os conhecimentos com a realidade" ${ }^{\text {. }}$.

\section{Notas}

1 UNIVERSIDADE FEDERAL DE SANTA CATARINA. Centro de Ciências da Educação. Atividades de extensão. Florianópolis, 1997. f. 3

2 UNIVERSIDADE FEDERAL DE SANTA CATARINA. Pró-Reitoria de Ensino de Graduação. Manual de monitoria e estágio. Florianópolis : UFSC, 1993.

3 UNIVERSIDADE FEDERAL DE SANTA CATARINA. Departamento de Biblioteconomia e Documentação. Coordenadoria de Estágios. Regulamento dos estágios do Departamento de Biblioteconomia e Documentação da Universidade Federal de Santa Catarina. Florianópolis, 1999. 4 Depoimento da aluna Silvia Luiza Pacheco, ao emitir avaliação da disciplina Estágio Supervisionado em Biblioteconomia do Curso de Biblioteconomia da UFSC, semestre 98.1

Disponibilizado na WWW em 26/04/1999. 